Pacific Journal of Mathematics

ACCELERATION BY SUBSEQUENCE TRANSFORMATIONS 


\title{
ACCELERATION BY SUBSEQUENCE TRANSFORMATIONS
}

\author{
Thomas A. Keagy and William F. Ford
}

\begin{abstract}
The acceleration field of subsequence matrix transformations are studied with respect to the convergence rate of the sequence being accelerated. Included is a proof that no subsequencing algorithm exists which will determine a set of subscripts $(n(i))$ for which $\left(y_{n(i)}\right)$ will be linear for every $y$ which converges at the same rate as or faster (slower) than a fixed sequence $x$.
\end{abstract}

1. Introduction. D. F. Dawson [2] has characterized the summability field of a matrix $A$ by showing $A$ is convergence preserving over the set of all sequences which converge faster than some fixed sequence $x, A$ is convergence preserving over the set of all sequences, or $A$ only preserves the limit of a set of constant sequences. We seek an analog to this result dealing with the acceleration field of a subsequence transformation.

The sequence $x$ converges to $\sigma$ faster than the sequence $y$ converges to $\lambda(x<y)$ if

$$
\lim _{n}\left(x_{n}-\sigma\right) /\left(y_{n}-\lambda\right)=0 .
$$

(In this case we also say that $y$ converges to $\lambda$ slower than $x$ converges to $\sigma$.) The matrix $A=\left(a_{p q}\right)$ accelerates the convergence of $x$ if $A x<x$. The acceleration field of $A$ is $\{x: A x<x\}$. The sequence $x$ converges to $\sigma$ at the same rate as the sequence $y$ converges to $\lambda$ $(x \approx y)$ if

$$
0<\frac{\lim }{n}\left|\left(x_{n}-\sigma\right) /\left(y_{n}-\lambda\right)\right| \leq \varlimsup_{n}\left|\left(x_{n}-\sigma\right) /\left(y_{n}-\lambda\right)\right|<+\infty .
$$

In $\S 2$ below, the basic background for investigating the acceleration field of a subsequence transformation in terms of rate of convergence is presented. The possibility of obtaining an analog to Dawson's result for the acceleration field of a subsequence transformation is considered in $\S 3$. Subsequences have been used by C. Brezinski, J. P. Delahaye, and B. Germain-Bonne [1] to generate an acceleration algorithm for a restricted class of sequences. In $\S 4$ it is shown that this algorithm cannot be extended to a larger class of sequences defined in terms of rate of convergence. 
2. Definitions and background. Most practical acceleration methods are nonlinear [9]. Exceptions include the familiar Euler tansformation [6] and its generalizations [11] which provide examples of linear methods useful for accelerating sequences of alternating terms [9], and the Salzer transformation [8] and its generalizations [10] which provide examples of linear methods useful for accelerating monotone sequences. In this work we will concentrate on the most basic linear acceleration method, subsequencing.

To simplify notation and ensure the existence of all quotients, we will restrict ourselves to the set $S_{0}$ of null sequences with nonzero terms. All results have analogs in the set of convergent sequences. Let $x, y \in S_{0}$ and define the intervals $(-, x),(x,-),(x, y),[x,-),(-, x]$, $[x, y],(x, y]$, and $[x, y)$ in the natural way using the order relation " $<$ " defined in $\S 1$ above. D. F. Dawson [2] has proved the following two results.

THEOREM 2.1 (Dawson). If $A$ is a convergence preserving for all $y \approx$ $x$, then $A$ is convergence preserving for all $z<x$.

THEOREM 2.2 (Dawson). If $A$ is convergence preserving for all $y \approx x$, then there exists $z>x$ such that $A$ is convergence preserving for all $y \approx z$.

It follows that $A$ is convergence preserving over a set of the type $(-, x)$. In the following section we seek analogs to these results dealing with acceleration rather than summability.

3. Subsequences. The subsequence $\left(x_{n(i)}\right)$ of $x$ can be represented as a regular matrix transformation $A$ times $x$ by letting $a_{i, n(i)}=1$ and $a_{p q}=0$ otherwise. It is clear that a subsequence can never converge slower than the original sequence. Some subsequences converge at the same rate and some converge faster than the sequence, but in every case $\underline{\lim }_{i}\left|x_{n(i)} / x_{i}\right| \leq 1$. The following three results show if $A$ is restricted to be a subsequence matrix, then an analog to Theorem 2.1 does not exist, but an analog to Theorem 2.2 does.

THEOREM 3.1. If $A$ is a subsequence transformation that accelerates $x \in S_{0}$, and $y$ is a sequence in $S_{0}$ such that $x \approx y$, then $A$ accelerates $y$.

Proof. The conclusion follows immediately from

$$
\frac{y_{n(i)}}{y_{i}}=\frac{y_{n(i)}}{x_{n(i)}} \cdot \frac{x_{i}}{y_{i}} \cdot \frac{x_{n(i)}}{x_{i}} \text {. }
$$


THEOREM 3.2. If $A$ is a subsequence transformation and $x \in S_{0}$, then there exist $y, z \in S_{0}$ such that $y<x<z$ and $A$ does not accelerate $y$ or $z$.

Proof. Let $A$ be the subsequence transformation defined by $(A x)_{i}=$ $x_{n(i)}$. Let

$$
y_{1}=y_{n(1)}=\min \left\{\left|x_{1}\right|^{2},\left|x_{n(1)}\right|^{2}\right\}
$$

and $y_{i}=\left|x_{i}\right|^{2}$ for $1<i<n(1)$. Let

$$
y_{n(1)+1}=y_{n(n(1)+1)}=\min \left\{\left|x_{n(1)+1}\right|^{2},\left|x_{n(n(1)+1)}\right|^{2}\right\}
$$

and $y_{i}=\left|x_{i}\right|^{2}$ for $n(1)+1<i<n(n(1)+1)$. Similarly, find $y_{n(n(1)+1)+1}$ $=y_{n(n(n(1)+1)+1)}$ and continue the process. It follows that $y<x$ and

$$
\varlimsup_{i}\left|y_{n(i)} / y_{i}\right| \geq 1 \text {, }
$$

hence $A$ does not accelerate $y$.

To find $x<z$, begin by letting $z_{1}=z_{n(1)}=\max \left\{\left|x_{1}\right|^{1 / 2},\left|x_{n(1)}\right|^{1 / 2}\right\}$ and $z_{i}=\left|x_{i}\right|^{1 / 2}$ for $1<i<n(1)$. Similarly, define $z_{n(1)+1}=z_{n(n(1)+1)}$ and continue the process. It follows that $x<z$ and $A$ fails to accelerate $z$.

THEOREM 3.3. If $A$ is a subsequence transformation and $x \in S_{0}$, then there exists $y \in S_{0}$ such that $y<x$ and $A$ accelerates $y$.

Proof. Let $y_{i}=\left|x_{i}\right|^{2}$ for $i<n(1)$ and $y_{n(1)}=\min \left\{y_{1},\left|x_{n(1)}\right|^{2}\right\}$. Let $y_{i}=\left|x_{i}\right|^{2}$ for $n(1)<i<n(2)$ and $y_{n(2)}=\min \left\{y_{2},\left|x_{n(2)}\right|^{2}\right\} / 2$. Continue the process, defining at each stage $y_{n(k)}=\min \left\{y_{k},\left.\left|x_{n(k)}\right|\right|^{2}\right\} / k$. It follows that $y<x$ and $A$ accelerates $y$, and the proof is complete.

No analog to Theorem 3.3 exists for $x<z$ as the following argument demonstrates. Let $A$ be a subsequence transformation with $A x=$ $\left(x_{n(i)}\right)$. If $A$ is the identity map, then $A$ fails to accelerate any sequence $x$. If $A$ is not the identity map, let $m=\min \{j: n(j)>j\}$, and define $(t(j))$ by $t(1)=n(m)$ and $t(k+1)=n(t(k))$ for $k=1,2,3, \ldots$ Let $x$ be the sequence given by $x_{i}=1$ if $i \leq t(1)$, and $x_{i}=1 / k$ if $t(k-1)<i \leq t(k), k=2,3,4, \ldots$ If $z \in S_{0}$ such that $x<z$, then $\lim _{k}\left|k z_{t(k)}\right|=+\infty$; hence, there exist an infinite number of $k$ such that $\left|(k+1) z_{t(k+1)}\right|>\left|k z_{t(k)}\right|$. It follows that

$$
\varlimsup_{k}\left|z_{t(k+1)} / z_{t(k)}\right|=\varlimsup_{k}\left|(k+1) z_{t(k+1)} / k z_{t(k)}\right| \geq 1,
$$

$A$ does not accelerate $z$, and the argument is complete. 
We thus have shown that the acceleration field of a subsequence transformation cannot be any of the forms $(-, x),(x,-),[x,-),(-, x]$, $(x, y),[x, y],(x, y]$, or $[x, y)$; nor can it include any of the first four of these forms. The following argument provides further insight into the central role of the form $(x, y)$ in characterizing the acceleration field.

Let $x \in S_{0}, A$ be a subsequence transformation that accelerates $x$, and $(A x)_{i}=x_{n(i)}=y_{i}$ for $i=1,2,3, \ldots$ If $\varepsilon_{i}=\left|y_{i} / x_{i}\right|$ for each $i$, then $\left(z_{i}\right)=\left(\sqrt{\varepsilon_{i}} x_{i}\right)$ satisfies $y<z<x$. Furthermore, if $z$ is any sequence satisfying $y<z<x$, then

$$
\frac{z_{n(i)}}{z_{i}}=\frac{z_{n(i)}}{x_{n(i)}} \cdot \frac{x_{n(i)}}{z_{i}}=\frac{z_{n(i)}}{x_{n(i)}} \cdot \frac{y_{i}}{z_{i}},
$$

which implies $A$ accelerates $z$. Similarly, define $\delta_{n(i)}=x_{i} / x_{n(i)}$ and $\delta_{j}=1 / \sqrt{\left|x_{j}\right|}$ otherwise. The sequence $\left(\delta_{k}\right)$ satisfies $\lim _{k}\left|\delta_{k}\right|=+\infty$ and $\lim _{i}\left(\delta_{n(i)} x_{n(i)} / \delta_{i} x_{i}\right)=0$. Also $\delta_{n(i)} x_{n(i)}=x_{i}$ for each $i$; hence, $A$ accelerates $\left(u_{n}\right)=\left(\delta_{n} x_{n}\right)$ and every $v$ such that $x<v<u$ by an argument similar to the one above for $y<z<x$.

The acceleration field for each $A$ is therefore the union of a collection of sets of the form $(x, y)$. Because every proper subsequence of $w=\left(1 / n^{n}\right)$ converges faster than $w$, it follows that the acceleration field of a subsequence transformation not equal to the identity cannot be empty. We thus have the following two results.

THEOREM 3.4. If $x \in S_{0}$ and $A$ is a subsequence matrix that accelerates $x$, then there exist $y$ and $z$ such that $y<x<z$ and $A$ accelerates each $w \in(y, z)$.

THEOREM 3.5. If $A$ is a subsequence matrix not equal to the identity matrix, then there exists $x \in S_{0}$ such that $A$ accelerates $x$.

The order of selection in Theorem 3.5 can be reversed. If $x \in S_{0}$, then there exists a subsequence matrix $A$ that accelerates $x$.

4. Logarithmic sequences. Let $x \in S_{0}$ such that

$$
\lim _{n} x_{n+1} / x_{n}=\sigma .
$$

If $\sigma \neq 0$ and $\sigma \neq 1$, then $x$ is said to converge linearly. If $\sigma=1$, then $x$ is said to converge logarithmically. The set of logarithmically convergent sequences is difficult to accelerate [3, 9]. C. Brezinski, J. P. Delahaye, and B. Germain-Bonne [1] have established the following result which leads to an acceleration algorithm for a proper subset of the set of logarithmically convergent sequences. 
Theorem 4.1 (Brezinski, Delahaye, Germain-Bonne). Let $x$ be a monotone logarithmically convergent element of $S_{0}$ and $\Gamma(x)=\{y \in$ $S_{0}$ : there exists $\lambda \neq 0$ such that $\left.\lim _{n} y_{n} / x_{n}=\lambda\right\}$. There exists an increasing sequence of positive integers $(n(i))$ such that for each $y \in$ $\Gamma(x),\left(y_{n(i)}\right)$ is linearly convergent.

Because acceleration methods (such as Aitken's $\Delta^{2}$ process) exist for linearly convergent sequences, the above theorem provides the first stage of an algorithm for accelerating the convergence of each element in $\Gamma(x)$. The following results show that this theorem cannot be extended by using a more general definition of the set $\Gamma(x)$ based on the convergence rate of $x$. (Note these results do not depend on $x$ being monotone or logarithmically convergent.)

THEOREM 4.2. Let $x \in S_{0},(n(i))$ be an increasing sequence of positive integers, and $T \subseteq \mathbf{R}$; then there exists $y<x(y>x)$ such that each $t \in T$ is a limit point of $\left(y_{n(i+1)} / y_{n(i)}\right)$.

Proof. We prove the case for $y<x$. The remaining case follows by a similar argument. Let $\left(u_{n}\right)$ be a countable subset of $\mathbf{R}-\{0\}$ that is dense in $T$. Let $\left(v_{n}\right)=\left(u_{1} ; u_{1}, u_{2} ; u_{1}, u_{2}, u_{3}, \ldots\right)$. Suppose the first $n(2 k-2)$ terms of $y$ have been chosen. Let

$$
\begin{aligned}
y_{n(2 k-1)}= & \min \left\{\left|x_{n(2 k)}^{2} / v_{k}\right|, x_{n(2 k-1)}^{2}, x_{n(2 k)}^{2}\right\}, \\
& y_{n(2 k)}=v_{k} \cdot y_{n(2 k-1)},
\end{aligned}
$$

and $y_{j}=x_{j}^{2}$ for $n(2 k-2)<j<n(2 k-1)$ and $n(2 k-1)<j<n(2 k)$. It follows that $y_{n(2 k)} / y_{n(2 k-1)}=v_{k},\left|y_{n(2 k-1)} / x_{n(2 k-1)}\right| \leq\left|x_{n(2 k-1)}\right|$, and $\left|y_{n(2 k)} / x_{n(2 k)}\right| \leq\left|x_{n(2 k)}\right|$. If this process is continued, then $y<x$ and each limit point of $T$ will be a limit point of $\left(y_{n(i+1)} / y_{n(i)}\right)$, and the proof is complete.

Corollary 4.3. If $x \in S_{0}$, then there does not exist an increasing sequence of positive integers $(n(i))$ such that $\left(y_{n(i)}\right)$ is linear for each $y<x(y>x)$.

The following results may be established by an argument similar to the one above.

THEOREM 4.4. Let $x \in S_{0},(n(i))$ be an increasing sequence of positive integers such that $\left(x_{n(i)}\right)$ is linear, and $T$ be a bounded subset of 
$\mathbf{R}$, then there exists $y \approx x$ such that each element of $T$ is a limit point of $\left(y_{n(i+1)} / y_{n(i)}\right)$.

CoROllaRy 4.5. If $x \in S_{0}$, then there does not exist an increasing sequence of positive integers $(n(i))$ such that $\left(y_{n(i)}\right)$ is linearly convergent for each $y \approx x$.

It follows that the set of logarithmically convergent sequences that a subsequence transformation maps into the set of linearly convergent sequences is more restrictive than the set of all $y \approx x$ or $y<x(x<y)$, where $x$ is some fixed sequence. It is thus impossible to express such a set as a union or intersection of collections of intervals.

\section{REFERENCES}

[1] C. Brezinski, J. P. Delahaye, and B. Germain-Bonne, Convergence acceleration by extraction of linear subsequences, Siam J. Numer. Anal., 20 (1983), 10991105.

[2] D. F. Dawson, Matrix summability over certain classes of sequences ordered with respect to rate of convergence, Pacific J. Math., 24 (1968), 51-56.

[3] J. P. Delahaye and B. Germain-Bonne, The set of logarithmically convergent sequences cannot be accelerated, Siam J. Numer. Anal., 19 (1982), 840-844.

[4] J. A. Fridy, Absolute summability matrices that are stronger than the identity map, Proc. Amer. Math. Soc., 47 (1975), 112-118.

[5] - Minimal rates of summability, Canad. J. Math., 30 (1978), 808-816.

[6] G. H. Hardy, Divergent Series, Clarendon Press, Oxford, 1949.

[7] R. E. Powell and S. M. Shah, Summability Theory and Applications, Van Nostrand Reinhold, London, 1972.

[8] H. E. Salzer, A simple method for summing certain slowly convergent series, J. Math. and Phys., 33 (1955), 356-359.

[9] D. A. Smith and W. F. Ford, Acceleration of linear and logarithmical convergence, Siam J. Numer. Anal., 16 (1979), 223-240.

[10] J. Wimp, Sequence Transformations and Their Applications, Academic Press, New York, 1981.

[11] P. Wynn, $A$ note on the generalized Euler transformation, Computer J., 14 (1971), 437-441.

Received February 23, 1987. The first author was supported by a NASA-ASEE fellowship at Lewis Research Center in Cleveland, Ohio while this work was performed.

DUQUESNE UNIVERSITY

PitTsBurgh, PA 15282

AND

National Aeronautics and Space Administration

LeWIS ReseARCH CENTER

Cleveland, OH 44135 


\title{
PACIFIC JOURNAL OF MATHEMATICS EDITORS
}

\author{
V. S. VARADARAJAN \\ (Managing Editor) \\ University of California \\ Los Angeles, CA 90024 \\ HERBERT Clemens \\ University of Utah \\ Salt Lake City, UT 84112 \\ R. FINN \\ Stanford University \\ Stanford, CA 94305
}

\author{
HERMANN FLASCHKA \\ University of Arizona \\ Tucson, AZ 85721
}

Ramesh A. Gangolli University of Washington Seattle, WA 98195

VAUGHAN F. R. JONES University of California Berkeley, CA 94720
ROBION KIRBY

University of California

Berkeley, CA 94720

C. C. MOORE

University of California

Berkeley, CA 94720

HAROLD STARK

University of California, San Diego La Jolla, CA 92093

\section{ASSOCIATE EDITORS}

\author{
R. ARENS \\ E. F. BECKENBACH \\ B. H. NEUMANN \\ F. WOLF \\ K. YOSHIDA \\ (1906-1982)

\section{SUPPORTING INSTITUTIONS}

\section{UNIVERSITY OF ARIZONA} \\ UNIVERSITY OF BRITISH COLUMBIA \\ CALIFORNIA INSTITUTE OF TECHNOLOGY \\ UNIVERSITY OF CALIFORNIA \\ MONTANA STATE UNIVERSITY \\ UNIVERSITY OF NEVADA, RENO \\ NEW MEXICO STATE UNIVERSITY \\ OREGON STATE UNIVERSITY \\ UNIVERSITY OF OREGON \\ UNIVERSITY OF SOUTHERN CALIFORNIA \\ STANFORD UNIVERSITY \\ UNIVERSITY OF HAWAII \\ UNIVERSITY OF TOKYO \\ UNIVERSITY OF UTAH \\ WASHINGTON STATE UNIVERSITY \\ UNIVERSITY OF WASHINGTON
}

The Supporting Institutions listed above contribute to the cost of publication of this Journal, but they are not owners or publishers and have no responsibility for its content or policies.

Mathematical papers intended for publication in the Pacific Journal of Mathematics should be in typed form or offset-reproduced (not dittoed), double spaced with large margins. Please do not use built up fractions in the text of the manuscript. However, you may use them in the displayed equations. Underline Greek letters in red, German in green, and script in blue. The first paragraph must be capable of being used separately as a synopsis of the entire paper. In particular it should contain no bibliographic references. Please propose a heading for the odd numbered pages of less than 35 characters. Manuscripts, in triplicate, may be sent to any one of the editors. Please classify according to the scheme of Math. Reviews, Index to Vol. 39. Supply name and address of author to whom proofs should be sent. All other communications should be addressed to the managing editor, or Elaine Barth, University of California, Los Angeles, California 90024

There are page-charges associated with articles appearing in the Pacific Journal of Mathematics. These charges are expected to be paid by the author's University, Government Agency or Company. If the author or authors do not have access to such Institutional support these charges are waived. Single authors will receive 50 free reprints; joint authors will receive a total of 100 free reprints. Additional copies may be obtained at cost in multiples of 50 .

The Pacific Journal of Mathematics is issued monthly as of January 1966. Regular subscription rate: $\$ 190.00$ a year (5 Vols., 10 issues). Special rate: $\$ 95.00$ a year to individual members of supporting institutions.

Subscriptions, orders for numbers issued in the last three calendar years, and changes of address should be sent to Pacific Journal of Mathematics, P.O. Box 969, Carmel Valley, CA 93924, U.S.A. Old back numbers obtainable from Kraus Periodicals Co., Route 100, Millwood, NY 10546.

The Pacific Journal of Mathematics at P.O. Box 969, Carmel Valley, CA 93924 (ISSN 0030-8730) publishes 5 volumes per year. Application to mail at Second-class postage rates is pending at Carmel Valley, California, and additional mailing offices. Postmaster: send address changes to Pacific Journal of Mathematics, P.O. Box 969, Carmel Valley, CA 93924.

PUBLISHED BY PACIFIC JOURNAL OF MATHEMATICS, A NON-PROFIT CORPORATION Copyright (C) 1988 by Pacific Journal of Mathematics 


\section{Pacific Journal of Mathematics}

\section{Vol. 132, No. $2 \quad$ February, 1988}

Jeffery Marc Bergen and Luisa Carini, A note on derivations with power central values on a Lie ideal ..............................209

Alfonso Castro and Sumalee Unsurangsie, A semilinear wave equation

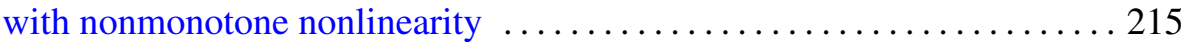

Marius Dadarlat, On homomorphisms of matrix algebras of continuous

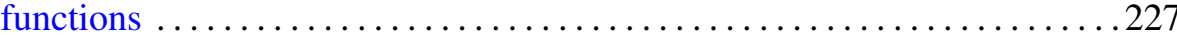

A. Didierjean, Quelques classes de cobordisme non orienté refusant de se

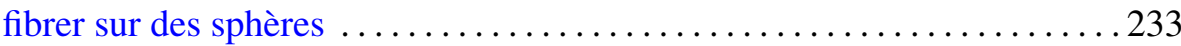

Edward George Effros and Zhong-Jin Ruan, On matricially normed spaces

Sherif El-Helaly and Taqdir Husain, Orthogonal bases are Schauder bases

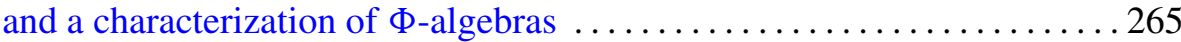

Edward Richard Fadell and Peter N-S Wong, On deforming $G$-maps to be

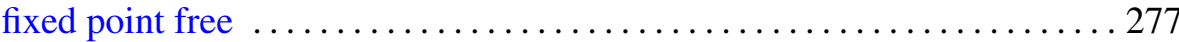

Jean-Jacques Gervais, Stability of unfoldings in the context of equivariant

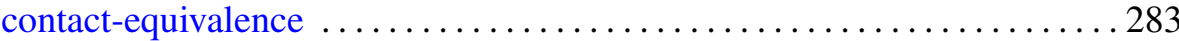

Douglas Martin Grenier, Fundamental domains for the general linear group

Ronald Scott Irving and Brad Shelton, Loewy series and simple projective

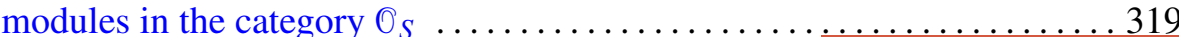

Russell Allan Johnson, On the Sato-Segal-Wilson solutions of the K-dV equation

Thomas Alan Keagy and William F. Ford, Acceleration by subsequence transformations

Min Ho Lee, Mixed cusp forms and holomorphic forms on elliptic varieties

Charles Livingston, Indecomposable surfaces in 4-space 